\title{
An Empirical Relation for Vegetation Fuel Flames Breakdown Electric Field Strength
}

\section{Kago Ernest Maabong, Kgakgamatso Mphale*, Douglas Letsholathebe, Samuel Chimidza, Phenyo Thebenyane}

Physics Department, University of Botswana, Gaborone, Botswana

Email: *mphalekm@mopipi.ub.bw

How to cite this paper: Maabong, K.E., Mphale, K., Letsholathebe, D., Chimidza, S. and Thebenyane, P. (2019) An Empirical Relation for Vegetation Fuel Flames Breakdown Electric Field Strength. Journal of Electromagnetic Analysis and Applications, 11, 187-202.

https://doi.org/10.4236/jemaa.2019.1111013

Received: August 30, 2019

Accepted: November 8, 2019

Published: November 11, 2019

Copyright $\odot 2019$ by author(s) and Scientific Research Publishing Inc. This work is licensed under the Creative Commons Attribution International License (CC BY 4.0).

http://creativecommons.org/licenses/by/4.0/

\section{Open Access}

\begin{abstract}
The compulsion to provide reliable electric power for sustenance of socioeconomic development is vital for most of southern Africa states. The demand for the resource in the region is anticipated to escalate in the next couple of decades. However, there is a deleterious effect of fire-induced power disruption which is observed in many countries. The mechanism through which the disruption occurs is currently a subject of current research in electric power distribution. It has been observed that streamer initiated conduction channel provides a means of high voltage electric power flashover. The main purpose of this study is to determine the empirical expression for breakdown electric field strength of vegetation fires. The breakdown field was measured from vegetation fuel (Peltophorum africanum) flames at different combustion temperatures. The data is essential for validation of simulation schemes which are necessary for evaluation of power grid systems reliability under extreme wildfire weather conditions. In this study, Peltophorum africanum fuels were ignited in a cylindrically shaped steel burner which was fitted with a Type-K thermocouple to measure flame temperature. The fuels consisted of dried fine twig $(\leq 0.8 \mathrm{~mm} \varnothing)$ and limb wood $(\geq 10 \mathrm{~mm} \varnothing)$ litter. Two copper pinned-electrodes supported by retort stands were mounted to the burner and energized to a high voltage. This generated a strong electric field sufficient to initiate dielectric breakdown in the flames. The measured electric field strength was plotted against flame temperatures and fit with a non-linear relation to give the empirical relation.
\end{abstract}

\section{Keywords}

Flashover, Wildfire, Flame Conductivity, Alkali Impurities, High Voltage, Thermal Ionization 


\section{Introduction}

Climate change has deleteriously affected terrestrial ecosystems. Its concomitant recurrent episodes of droughts and extreme heat have led to environmental conditions, which are conducive to the occurrence of frequent large wildfires [1]. Occasionally, the fires burn under or in propinquity to high-voltage transmission lines when there is luxuriant re-sprouted vegetation in right-of-way, e.g. such as shown in Figure 1. This affects the reliability of electrical power supply as this may lead to the utility disruption. A significant number of fire-induced power outages have been reported in several countries [2] [3] [4]. For instance, in South Africa, vegetation fires are responsible for about $22 \%$ of annual transmission line faults [4].

The faults are normally due to short-circuiting between conductor phases or conductor-to-ground discharges at mid-span region of the high-voltage transmission system. Research has shown that wildfire plumes provide a conductive path for the discharge [2] [3]. The conductor-to-ground flashover may possibly be a safety concern for fire-fighters who may be within an arcing zone during suppression [2].

A mechanism by which fire-induced power loss occurs is still not clearly understood [5] [6]. However, three models are currently used to explain the power loss. The models are summarized below as:

1) Reduced air density model: heat from the fires increases temperature in the air gap (i.e., between energised conductors and the ground). This lowers the air density and consequently decreases its insulation strength by up to $50 \%$ [7].

2) Particle initiated flashover: thermal plumes from the vegetation fires carry soot and ash particles aloft. The particles distort and intensify electric field in the air gap. This consequently leads to power loss when breakdown electric field is exceeded [3].

3) Flame conductivity model: intense heat in combustion zone of the fire

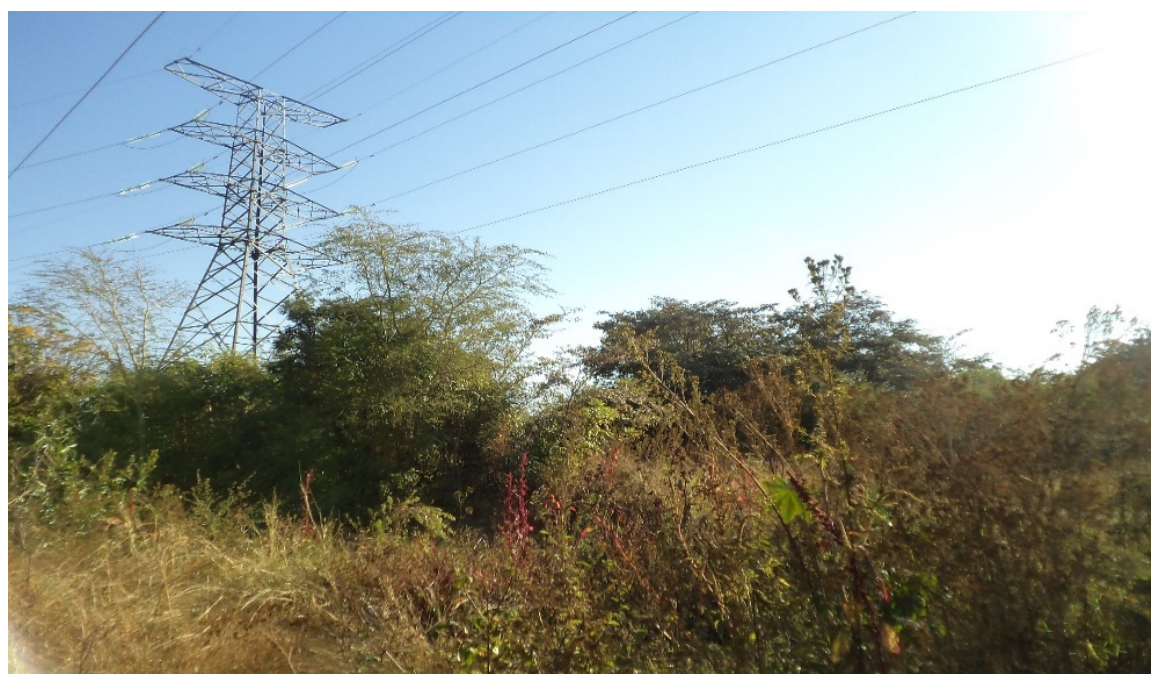

Figure 1. Luxuriant vegetation under high voltage transmission power lines. 
creates ions and electrons from flame inherent particulates. Increase in the ion and electron concentration increases the electrical conductivity of the fire plume [5].

The fire-induced particle initiated flashover model and its associated critical flashover voltage has been clearly elucidated by several researchers, e.g., [8] [9]. The theory of reduced air density has been expounded by (Robledo-Martinez \& Guzman, [7]). However, very few attempts have been made to explicate flame conductivity model, e.g. in [5]. Even though there is no consensus as to which model is predominant, several researchers acknowledge that temperature and ionisation are major factors that influence to fire-induced flashover, e.g. in $\mathrm{Wu}$ et al. [10]. Moreover, it has been illustrated from field experiments that flame conductivity plays major role in fire-induced flashover.

Several experiments have been conducted to measure breakdown voltage for vegetation fires under different conditions, e.g. [3] and [6]. Nevertheless, there is paucity of experimental data on breakdown electric field in flame medium. Maabong et al. [11] observe that breakdown electric field strength is crucial for initiation of electrical discharge mechanism for conduction in fluids or in streamers propagation in flames. The data is essential for validation of simulation schemes which are necessary for evaluation of power grid systems reliability under extreme wildfire weather conditions. Despite this, there is paucity of data on breakdown electric field strength for vegetation fires.

It is intended in the study to: 1) measure dielectric breakdown electric field for vegetation fuel flames at atmospheric pressure and different combustion temperatures; 2) derive an empirical expression that relates breakdown electric field with vegetation fuel flame temperature. The expression is compared to similar ones in for other gas mixtures, e.g. Nitrogen, Oxygen and Carbon dioxide. Section 2 of the manuscript discusses ionization vegetation fuel flames. Classical electrodynamics and electrical discharge theories are applied to derive an expression for critical electric field in Section 3. In Section 4, combustion experiments to measure breakdown electric field and chemical equilibrium calculations are described. The results are discussed in Section 5 and the manuscript is concluded in Section 6 with a suggestion of future research directions on the subject.

\section{Ionization in Vegetation Fire}

\subsection{Combustion of Vegetative Material}

When subjected to intense heat, vegetation undergoes three interconnected temperature-dependent decomposition stages (Morvan \& Dupuy, [12]). The decomposition stages lead to the development of fire and influence its rate of spread through vegetation. The stages are shown in Figure 2 as: drying (A), pyrolysis (B) and char oxidation (C).

The combustion behavior depends on moisture, ash composition and prevalent combustion conditions. Proximate analysis shows that a significant proportion 


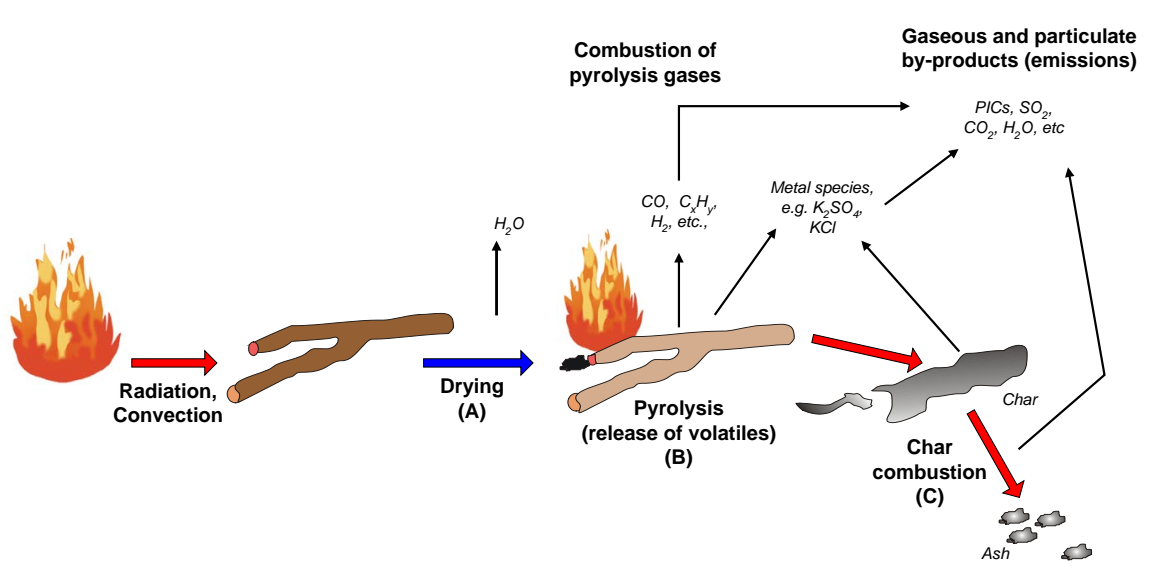

Figure 2. Mechanism of thermal degradation of vegetation.

( $>60 \%)$ of vegetative matter is made of complex volatiles [13]. Nussbaumer [14] estimates that combustion of vegetation matter could proceed by the following reaction equation:

$$
\begin{aligned}
& \mathrm{CH}_{1.44} \mathrm{O}_{0.66}+\lambda 1.03\left(\mathrm{O}_{2}+3.76 \mathrm{~N}_{2}\right) \\
& \Rightarrow \text { intermediates }\left(\mathrm{C}, \mathrm{CO}, \mathrm{H}_{2}, \mathrm{CO}_{2}, \mathrm{C}_{m} \mathrm{H}_{n} \text {, etc }\right) \\
& \Rightarrow \mathrm{CO}_{2}+0.72 \mathrm{H}_{2} \mathrm{O}+(\lambda-1) \mathrm{O}_{2}+\lambda 3.87 \mathrm{~N}_{2}
\end{aligned}
$$

The first reactant in Equation (1) is the average formula for biomass material. The excess air ratio is depicted by $\lambda$. The equation illustrates several by-products of incomplete combustion (intermediates) which are released into the atmosphere in form of a thermal plume. The intermediates include inorganic salts of alkalis, carbon monoxide, oxides of nitrogen, pyrogenic (organic and black) carbon, polycyclic aromatic hydrocarbons as well as volatile organic compounds, which are not shown in the equation (Reid et al., [15]).

\subsection{Ionization Processes in Fire}

Latham [16] identifies two major mechanisms that produce charged particles in vegetative fuel flames. These processes are flame temperature dependent and have been identified as thermal and chemi-ionization.

\subsubsection{Thermal Ionisation}

Vegetative fuel fires are considered impure hydrocarbon diffusion flames seeded with Alkali-Alkaline Earth Metals (A-AEM) based nutrients [17]. In plants, about $90 \%$ of A-AEM exist in aqueous form, e.g., as companions of anions such as chlorides and sulphates or as cations of complexes such lactone and carbonyl forming weak ionic bonds. The A-AEM species could also exist as discrete salt particles in plants organic matrix, e.g. calcium oxalate.

During flaming a significant number of A-AEMs are volatilised from a thermally decomposing vegetative matter and drawn into the reaction zone by local convective currents of the fire. A major fraction of the volatilised species is potassium-based salts [18]. However, at temperatures lower than $500 \mathrm{~K}$, charcoal is 
formed at the wood surface and this traps A-AEMs in organic matrix voids. The trapped A-AEMs react with functional groups such as carboxyl and carbonyl (O-C-) on the inner charcoal surface to form Charcoal Matrix Attached Alkalis (CharM-A). As the combustion temperature rises above $500 \mathrm{~K}$, cellulose and lignin rapidly disintegrate, a process which results in the formation of a highly reactive hydrogen radical $(\mathrm{H})$. The radical reacts the CharM-A species to give A-AEM atoms according to the following reaction equation (Okuno et al., [19]):

$$
\text { CharM-A (s) }+\mathrm{H}(\mathrm{g}) \Leftrightarrow \text { CharM-H(s) }+\mathrm{A}(\mathrm{g})
$$

Since the element potassium exists in significant amounts in vegetation [20] and has low ionisation potential of $4.34 \mathrm{eV}$, it is assumed that thermal ionisation in the fires is predominately due to the element. The very hot environment thermally excites potassium particulates $(\mathrm{K}(\mathrm{g}))$, and consequently thermally ionise them to produce electrons and ions by the following process:

$$
\mathrm{K}(\mathrm{g}) \Leftrightarrow \mathrm{K}^{+}(\mathrm{g})+\mathrm{e}^{-}
$$

\subsubsection{Chemi-Ionization}

One of the major contributors to ions in flames is energised methyl radical $\mathrm{CH}^{\star}$ [21]. The excited $\mathrm{CH}$ radical reacts with oxygen atoms in the flame to produce $\mathrm{CHO}^{+}$, a primary ion in flames and electrons according to the following reaction equation:

$$
\mathrm{CH}^{*}+\mathrm{O} \Leftrightarrow \mathrm{CHO}^{+}+\mathrm{e}^{-}
$$

For chemi-ionization reaction mentioned above, temperature and concentration of species hinder their contribution to ionization. For example, in Equation (4), the availability of $\mathrm{O}$ atoms is temperature and species concentration dependent.

\section{Theoretical Consideration}

\subsection{Critical Breakdown Electric Field}

Consider a homogeneous, non-magnetized weakly ionized wildfire plume which is illuminated with a strong electric field of the form: $E=E_{0} \exp (i \omega t)$, produced from an energized electrode. Since the plume is weakly ionized, dominant mode of particle interaction is elastic collisions between electrons and inherent neutral particulates. A dynamical equation that describes the motion of the electrons in the plume is given by Langevin equation as:

$$
m_{e} \frac{\mathrm{d}^{2} r}{\mathrm{~d} t^{2}}=-q_{e} E-\varphi_{e f f} m_{e} \frac{\mathrm{d} r}{\mathrm{~d} t}
$$

Solving for the position vector $(r)$ and drift velocity $\left(\frac{\mathrm{d} r}{\mathrm{~d} t}\right)$ of the electrons from (5) gives:

$$
r=\frac{q_{e} E}{m_{e} \omega\left(\omega-i \varphi_{e f f}\right)}
$$


and

$$
\frac{\mathrm{d} r}{\mathrm{~d} t}=\frac{-q_{e} E}{m_{e}}\left\{\frac{\left(\varphi_{\text {eff }}-i \omega\right)}{\left(\omega^{2}+\varphi_{\text {eff }}^{2}\right)}\right\}
$$

The wildfire plume is a mixture of several gases; therefore, its momentum transfer collision frequency is an average of individual gas contribution. The effective collision frequency is calculated from the relation (Letsholathebe \& Mphale, [22]):

$$
\varphi_{\text {eff }}=\bar{v} N_{g} \sum_{i} n_{i} Q_{i}
$$

where thermal velocity of the electron gas is $\bar{v}=\left(2 k_{B} T_{f l} / m_{e}\right)^{1 / 2}$.

At low electromagnetic wave radial propagation frequencies $(\omega)$ far much less $\varphi_{\text {eff }}$ i.e., $\left(\omega \ll \varphi_{\text {eff }}\right)$ and if the applied electric field is not strong enough to accelerate electrons between collisions, then Equation (5) reduces to:

$$
m_{e} u_{d} \varphi_{\text {eff }}=e E
$$

where $-e$ and $u_{d}$ have been substituted for $q$ and $\frac{\mathrm{d} r}{\mathrm{~d} t}$, respectively.

The LHS of (9) is the dynamic frictional force on electron fluid $\left(F_{b r}\right) . E$ becomes the critical breakdown electric field strength $\left(E_{c r}\right)$.

\subsection{Attachment and Ionisation Rates}

However, if the incident electric field is considered to be strong enough to accelerate electrons between successive collisions. The electrons may acquire energy greater than the ionization energy of flame neutrals. Some of the electrons will then ionize the neutrals to form positive ions and additional electrons as they move towards complementary electrode, i.e. anode electrode. Depending on the energy gained from the field, the additional electrons may undergo further ionizing collisions as they are also accelerated towards the anode. The process develops into electron avalanches which sequentially transform into a filamentary conductive plasma channel that elongates at a very high speed to bridge the gap between the two electrodes. To describe the ionization process that leads to the avalanche processes, Townsend ionization coefficient $(\alpha)$ is used and is given as:

$$
\alpha\left(\chi_{\alpha}\right)=A \exp \left(-\frac{\delta}{\chi_{\alpha}}\right)
$$

Similarly, electrons in the flame medium attach to particulates that have high electron affinity and attachment cross section. The attachment coefficient can be expressed as:

$$
\beta\left(\chi_{\beta}\right)=B \exp \left(-\frac{\gamma}{\chi_{\beta}}\right)
$$

The critical point at which the flame changes from non-conducting to conducting state (i.e. breakdown) occurs when $\beta\left(\chi_{e}\right)=\alpha\left(\chi_{e}\right)$. At this point, 


$$
A \exp \left(-\frac{\delta}{\chi_{\alpha}}\right)=B \exp \left(-\frac{\gamma}{\chi_{\beta}}\right)
$$

Re-arranging (12) gives relation (13) from which electron temperature is obtained after fitting relations (10) and (11) to experimental data, e.g. data obtain from chemical equilibrium calculations $\left(\mathrm{GASEQ}^{\circledR}\right)$.

$$
\ln \left\{\frac{A}{B}\right\}=\frac{\left(\delta \chi_{\beta}-\gamma \chi_{\alpha}\right)}{\left(\chi_{\alpha} \chi_{\beta}\right)}
$$

In the Townsend attachment and ionization rates (Equation (10) and (Equation (11)), $\chi_{a}$ and $\chi_{\beta}$ are in the form: $T_{e}+a$ and $T_{e}+b$, respectively. Where $T_{e}$ is electron temperature and constants $a$ and $b$ are obtained from nonlinear fit of the simulated data. The solution of (13) of the form [23]:

$$
T_{e}=9.14 \times 10^{-5} \frac{E}{P} \frac{\eta T_{r}}{T_{f l}}
$$

\section{Experimental Methods}

\subsection{Electrical Determination of Breakdown Field Strength}

The experimental set up for combustion of the weeping wattle (Peltophorum africanum) litter fall is shown in Figure 3. It consisted of a cylindrical steel burner of diameter $10 \mathrm{~cm}$ and height $14 \mathrm{~cm}$. Eight (8) holes of diameter $1.2 \mathrm{~cm}$ were diametrically drilled at about $2 \mathrm{~cm}$ from the bottom edge of the burner to allow influx of air into the combustion area. The burner was fitted with a Type-K thermocouple for measurement of temperature at the seat of the flame. A PASCO ${ }^{\circledR}$ lab jack (SE-9373), with a ceramic tile on its platform, provided a levelled surface for placing the burner and litter for combustion (see Figure 3 ). The tile is a good heat insulator and was therefore used to protect the platform from high flame temperatures. The burner was also fitted with two (2) copper electrodes $(0.80 \mathrm{~cm}$ $\varnothing)$ for providing strong electric field to the flame medium.

The two copper electrodes had hemispherical tips of diameter $0.06 \mathrm{~cm}$ and were held in position by insulated retort stand clamps. The electrodes were inserted into the burner through the diametrically oppose holes. This allowed the distance between them to be varied. In the experiments a constant inter-electrode distance was set to $0.11 \mathrm{~cm}$ The electrodes were connected to opposite terminals of a PHYWE ${ }^{\circledR}$ high voltage dc power supply. The capacity of the power supply was a potential difference of $10 \mathrm{kV}$ and had a current surge protector. The connection is shown in the experimental set up (Figure 3 ).

The litter fall (fuel) consisted of fine twigs $(\leq 0.8 \mathrm{~mm} \emptyset)$ and limb wood $(\geq 10$ $\mathrm{mm} \emptyset$ ). It was dried for two days before the experiment. This was done to increase combustion efficiency during the experiment. The dried fuel, bundled by a fine thread to a diameter of about $4 \mathrm{~cm}$ and height $7.5 \mathrm{~cm}$ (see Figure 4), was placed into the cylindrical burner. The height of the bundle was set based on the need for its end to coincide with the position of the electrodes and the thermocouple bulb, which should be at the reaction zone of the flame. Wooden guides 


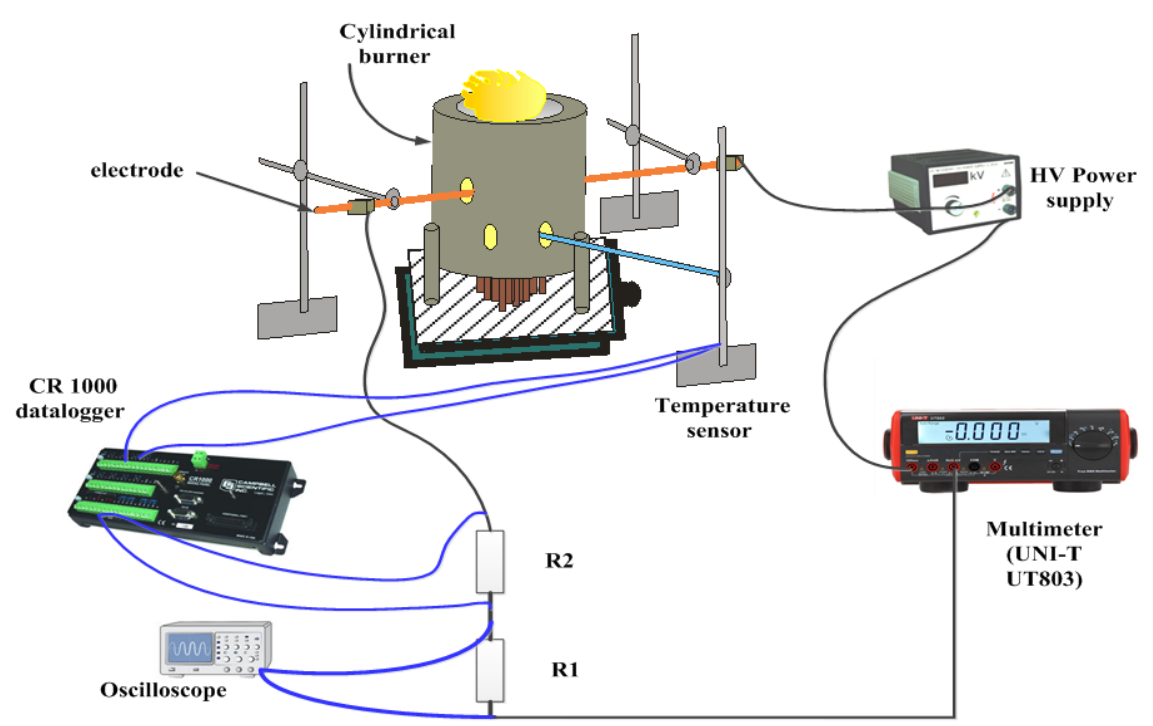

Figure 3. Experimental set up for measurement of breakdown electric field strength for wattle flame.

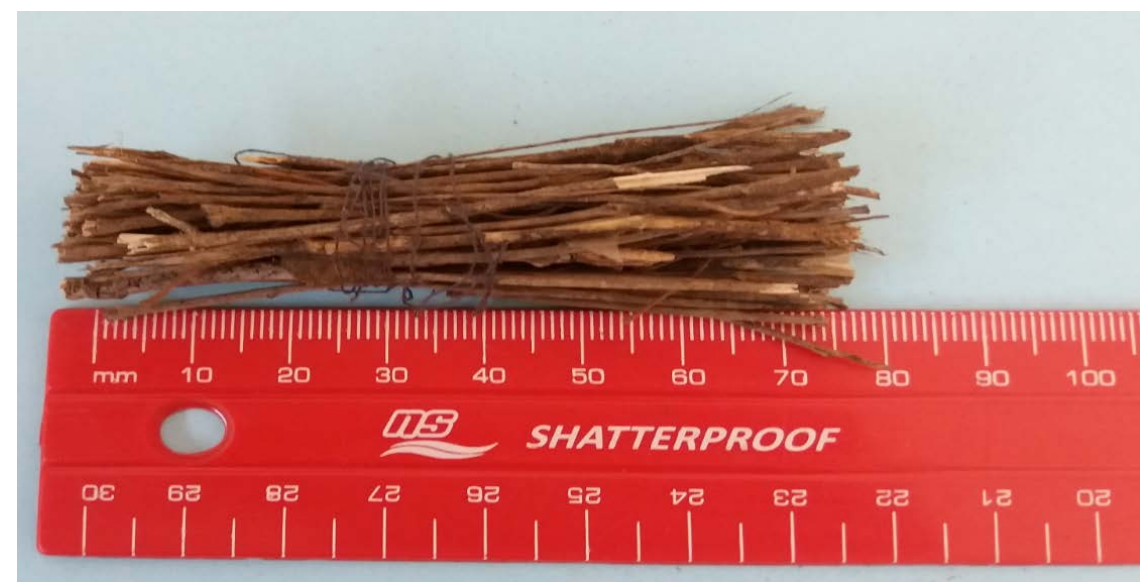

Figure 4. Combustion fuel (weeping wattle fine twigs) used for breakdown electric field measurement.

were provided so that the fuel is perpendicular to the jack surface so that the flame is not tilted.

Once secured in position within the burner, the fuel was ignited. The electrodes were then energized. Potential difference between the electrodes was increased steep-wise during combustion at a constant rate of $0.3 \mathrm{kV}$ every 10 seconds. As the potential difference between the electrodes was raised, its accurate value was recorded and observed from Campbell Scientific CR1000 data logger and a Cathode Ray Oscilloscope, respectively. The data logger also read in the flame seat temperature from the thermocouple. At breakdown voltage, a sudden increase in current was registered in the sensitive multimeter as the flame becomes conductive. There was also a sudden drop in potential difference across $\mathrm{R} 2$ as the load becomes less resistive. The experiment was repeated several times under different combustion conditions. 


\subsection{Simulation of Breakdown Field Using Chemical Equilibrium Calculation Method}

Intense temperature observed in vegetation fires is mainly due to pyrolysis of cellulose in the biomass fuel. Research has shown that major components in the pyrolysis mixture are; $\mathrm{CO}_{2}, \mathrm{H}_{2}, \mathrm{CH}_{4}, \mathrm{H}_{2} \mathrm{O}$ and $\mathrm{CO}$ [24]. Using representative pyrolysis gas, e.g. in [25], as reactants in a chemical equilibrium software GASEQ $^{\circledR}$, several combustion products were obtained as shown in Table 1 . The table gives the products in terms in mole fractions (note that inclusion of potassium $(\mathrm{K})$ in the mixture). GASEQ ${ }^{\circledR}$ is a chemical equilibrium software that calculates gas phase adiabatic composition and temperature at a given pressure. It uses the method of minimization of free energy to calculate the equilibrium composition at a specified temperature (Morley, [26]). This facilitates calculation of ionization and attachment rates required for the determination of the critical breakdown electric field, e.g. in Uhm (1999).

The variation of ionization and attachment rates with electron temperature was simulated using the gas mole fractions from GASEQ ${ }^{\circledR}$, collision and attachment cross-section are given in literature, e.g. Itakawa [27].

\section{Results and Discussions}

\subsection{Combustion Behavior of Fuels}

Three (3) fine twig and five (5) limb wood Peltophorum africanum fuel combustion experiments were carried out in the study. The samples were labelled $\boldsymbol{A}$ to $H$ depending on the order of ignition, i.e. a sample was labelled $A$ because it was ignited first. The fires of various intensities and heights were observed during the experiment. By visual inspection, the heights ranged from about the top of the rim $(14 \mathrm{~cm})$ to $20 \mathrm{~cm}$ from the PASKO ${ }^{\circledR}$ lab jack platform. Temperatures were measured at the fuel-flame interface during combustion. Twig fuels took 45 - 62 seconds to reach maximum flame temperature while limb wood took much longer. Figure 5 and Figure 6 show a typical fine twigs sample $(B)$ whose temperature rose quickly to reach maximum of $1022 \mathrm{~K}$ in a time of 50 seconds after

Table 1. Vegetation fuel flame composition at $1300 \mathrm{~K}$.

\begin{tabular}{cc}
\hline Flame composition & Mole fractions of the components \\
\hline $\mathrm{N}_{2}$ & 0.389 \\
$\mathrm{H}_{2} \mathrm{O}$ & 0.158 \\
$\mathrm{CO}_{2}$ & 0.108 \\
$\mathrm{CO}$ & 0.188 \\
$\mathrm{O}_{2}$ & $7.492 \times 10^{-15}$ \\
$\mathrm{OH}$ & $5.906 \times 10^{-9}$ \\
$\mathrm{H}$ & $4.363 \times 10^{-7}$ \\
$\mathrm{O}$ & $1.516 \times 10^{-14}$ \\
$\mathrm{H}_{2}$ & 0.157 \\
$\mathrm{NO}$ & $5.758 \times 10^{-11}$ \\
$\mathrm{~K}$ & $2.000 \times 10^{-5}$
\end{tabular}

Note: the mole fractions were calculated using GASEQ ${ }^{\circledR}$ software. 


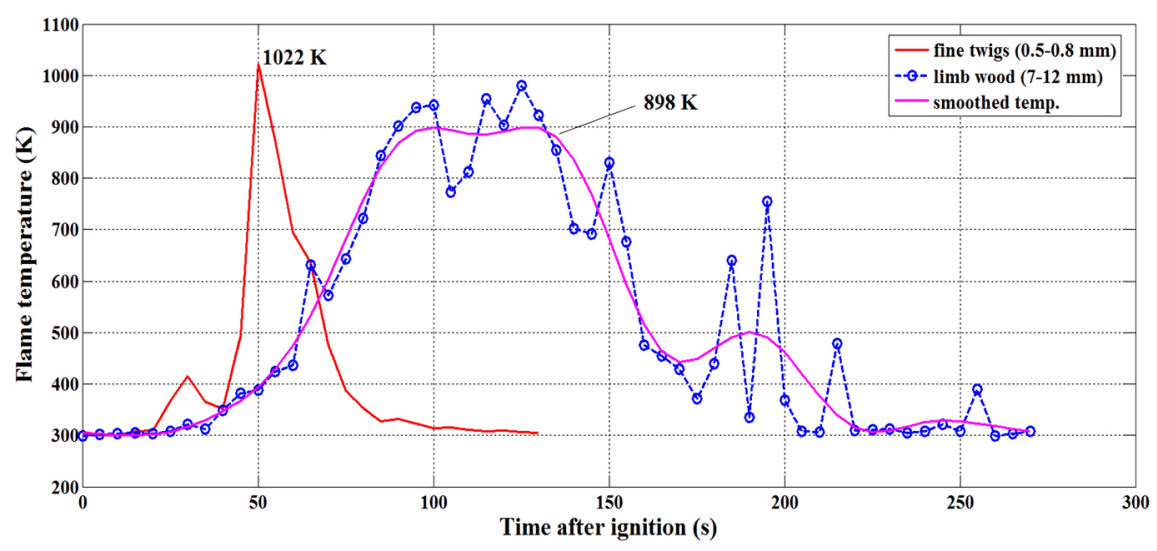

Figure 5. Variation of combustion temperature of samples $\boldsymbol{B}$ and $\boldsymbol{F}$ with time.

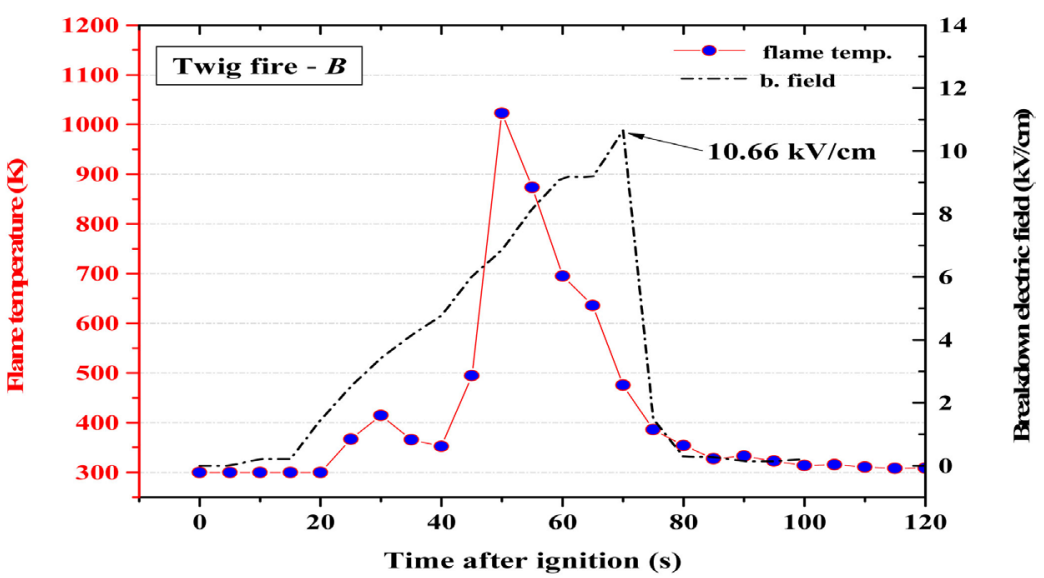

Figure 6. Combustion fuel (weeping wattle, fine twigs) used for breakdown electric field measurement.

ignition. Twig samples $\boldsymbol{A}$ and $\boldsymbol{C}$ burned less vigorously to a maximum temperatures of 751 and $987 \mathrm{~K}$, respectively. The heights of the flames were, by visual inspection, 15 and $17 \mathrm{~cm}$, respectively. Except for samples $G$ and $H$, limb wood fuels $(D-F)$ produced cooler and steady flames with an average maximum temperature of 624,672 and $898 \mathrm{~K}$, respectively. This occurred at the times of 146 , 151 and 128 seconds after ignition, respectively (see Figure 5 for sample $F$ ). This could be explained by the fact that thermal decomposition of the fine twigs fuel matrix disintegrated quickly to release combustible volatiles faster than that of limb wood fuel.

\subsection{Breakdown Electric Field}

At about 4 - 6 seconds after the fuels were ignited, the electrodes (with hemispherical tip) were energized by applying high voltage potential difference at a steady rate of $0.03 \mathrm{kV}$ per second. The applied voltage generated electric field of the form:

$$
E_{e p}=\frac{\phi_{p}}{\rho} \mu
$$


where:

$$
\begin{gathered}
\mu=\left\{\frac{t}{t^{2}-x^{2}}\right\}, \\
\rho=\ln \left(\frac{1+\Gamma}{1-\Gamma}\right), \\
t=(0.5 d)\{(0.5 d)+R\}^{0.5} \\
\phi_{\text {crit }}=\left\{\left(\frac{R_{1}}{R_{2}}\right)+\phi_{2 c r i t}\right\}
\end{gathered}
$$

where $d, \phi_{2 c r i t}$ and $R$ are inter-electrode gap, potential difference across R2 at breakdown and radius of curvature for the electrode tip, respectively.

The breakdown voltage $\left(\phi_{\text {crit }}\right)$ was determined from potential difference across R2, which was recorded in the data logger. A typical variation of electrical field between the electrodes immersed in twig flames is shown in Figure 6. The figure shows that for the particular experiment, breakdown occurred after the flame peak temperature (at 72 seconds) and was of value $10.7 \mathrm{kV} / \mathrm{cm}$.

Figure 7 shows that occurrence of breakdown for limb wood flame was at 151 seconds. Its value was noted to be $13.5 \mathrm{kV} / \mathrm{cm}$. It took average of about 78 seconds for twig fuel flames and 156 seconds for limb wood to conduct electricity.

The measured breakdown electric field strengths from the fires were plotted against the maximum temperature attained in the experiments (Figure 8). A nonlinear fit of the data $(r=0.93)$ shows that breakdown field varies inversely the flame temperature $\left(T_{f f}\right)$, i.e. $E_{b r}=40 / T_{f f} \mathrm{kVcm}^{-1}$. When the empirical expression is compared with other theoretical models [23], the empirical model coefficient is higher. The coefficients for Uhm and Pasko models are 25.2 and 32 $\mathrm{kVcm}^{-1}$, respectively.

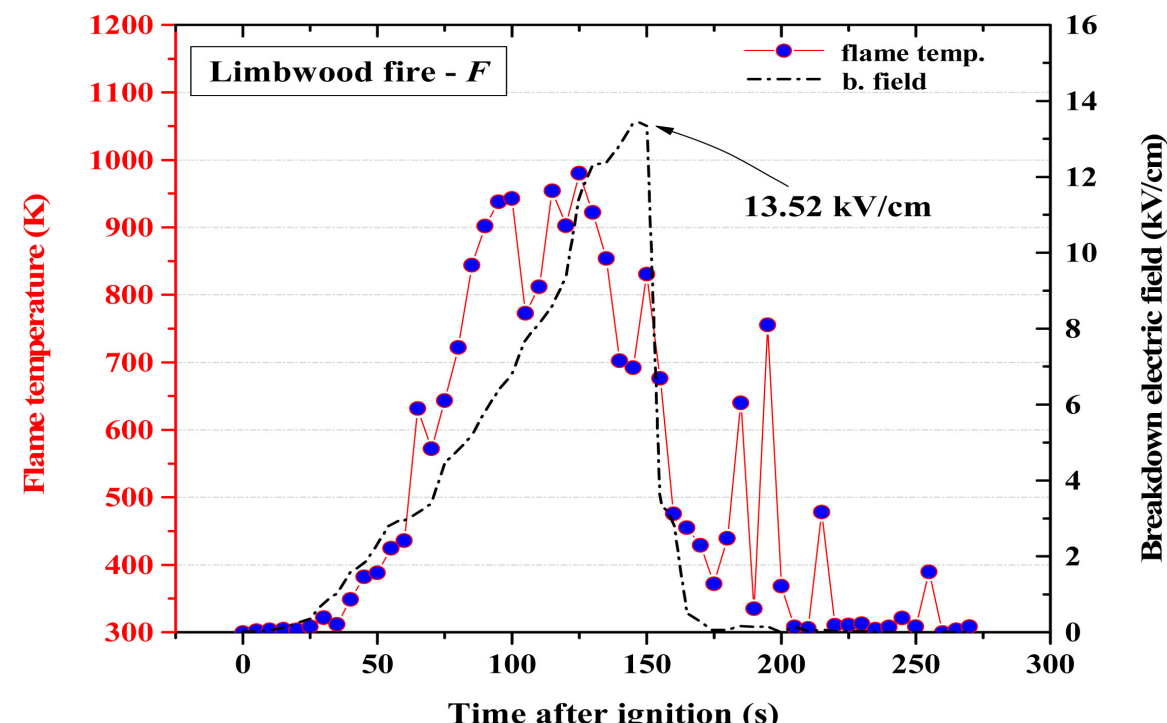

Figure 7. Combustion fuel (weeping wattle, limb wood) used for breakdown electric field measurement. 


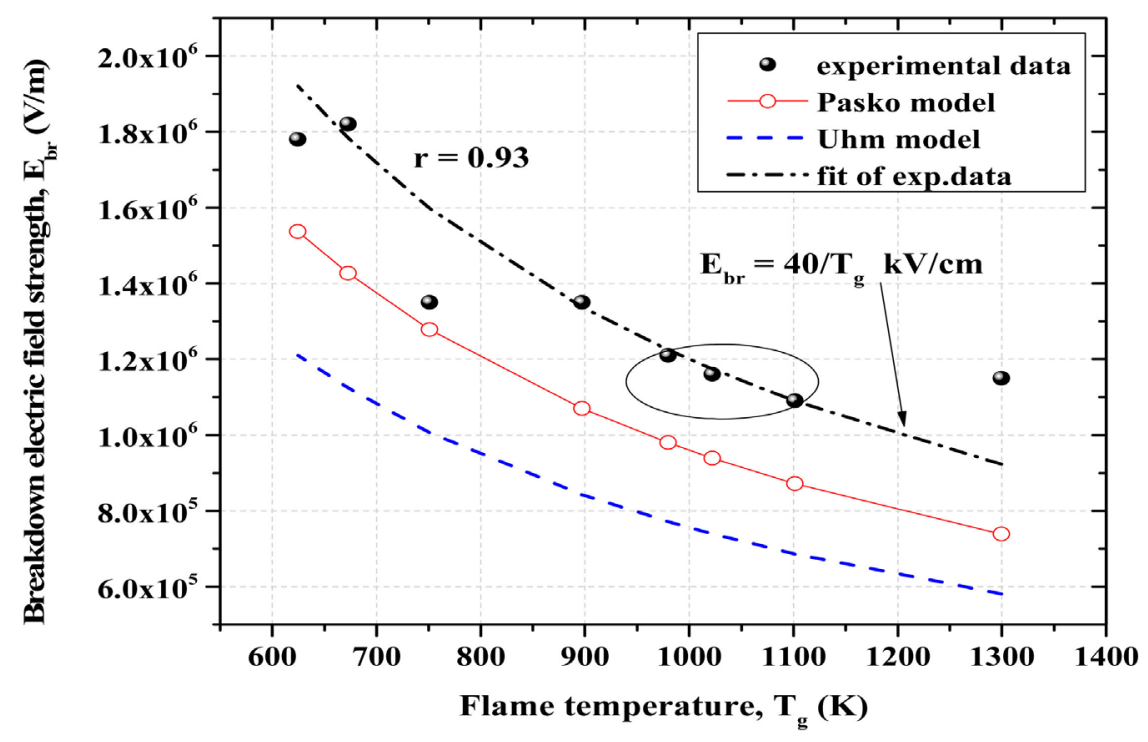

Figure 8. Combustion fuel (weeping wattle fine twigs) used for breakdown electric.

However, it has been shown by Heylen et al. [28] that under similar condition, hydrocarbons with higher molecular weight have higher breakdown electric field strength compared to lighter ones. As discussed in Section 2 of the manuscript, vegetation fires are impure hydrocarbon flames therefore will have higher breakdown electric field strength compared to dry air. Besides Hirano [29] and Chandra et al. [30] obtained breakdown electric field strength of $9-10 \mathrm{kV} / \mathrm{cm}$ for a seeded hydrocarbon flames.

\subsection{Prediction of Critical Electric Field Strength}

1) Braking force method

Streamers are basic modes through which electrical conduction occurs in fluids. Chen et al. [31] derived an empirical relation between steamer velocity $\left(u_{s}\right)$ with its diameter, vis, $u_{s}=0.3+0.59 d_{s} \mathrm{~mm} \cdot \mathrm{ns}^{-1}$. Using streamer radius $r_{s}$ of $1.4 \mathrm{~mm}$ for fields around $10 \mathrm{kV} / \mathrm{cm}$ [32], one obtains $u_{s}=u_{d}$ of $1.95 \times 10^{6} \mathrm{~m} / \mathrm{s}$. Assuming momentum transfer collision frequency of $1 \times 10^{11} \mathrm{~s}^{-1}$ in fire, e.g. in [33], Equation (12) gives the critical electric field strength of $11.09 \mathrm{kV} / \mathrm{cm}$.

2) Chemical equilibrium calculation (CEC) method

The simulated data for ionization rate $(\alpha)$ was fit with relation (10) while attachment rate with was with relation (11) (see Figure 9 and Figure 10).

Uhm [23] notes that; for dry air at breakdown, electron temperature is $2.3 \mathrm{eV}$. Therefore, the region of interest for ionization and attachment rates in vegetation fires from figures is that for which electron energies are greater than $2.0 \mathrm{eV}$.

Table 2 shows the coefficient from the fit and the Pearson correlation $(r)$ of the fit. When the coefficients are inserted into Equation (10) and Equation (11) and the equations solved for $T_{e}$, a value of $3.1 \mathrm{eV}$ is obtained. However, electron temperature for hot gases is related to the breakdown electric field by the relation [23]: 


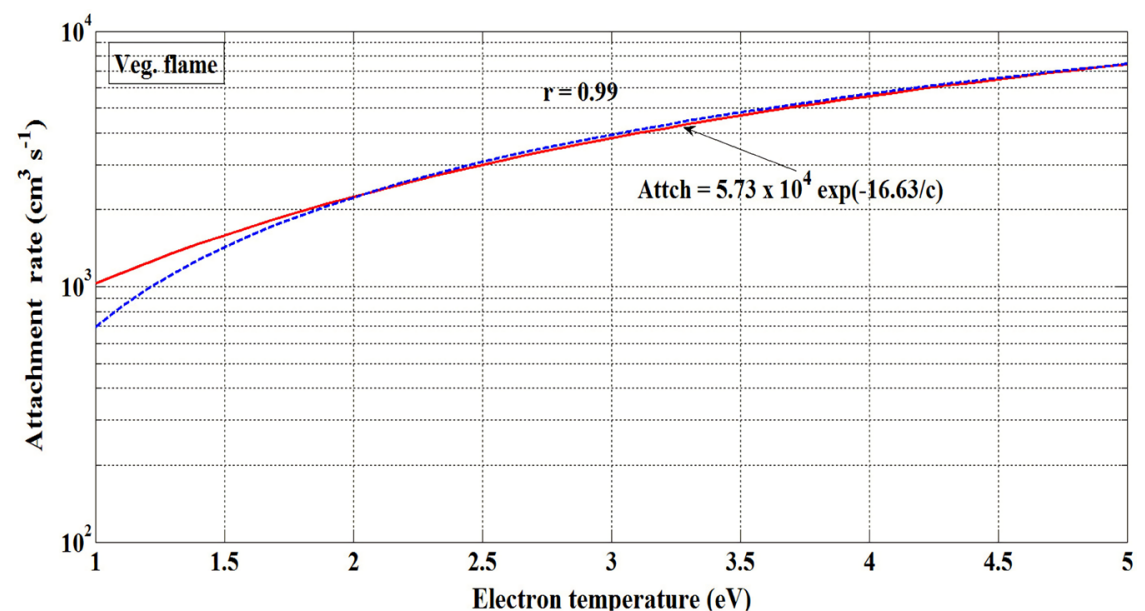

Figure 9. Attachment rate of electrons in vegetation fuel flame (red solid line is for emperical relation and blue dotted line for theoretical relation (after Uhm, 1999)).

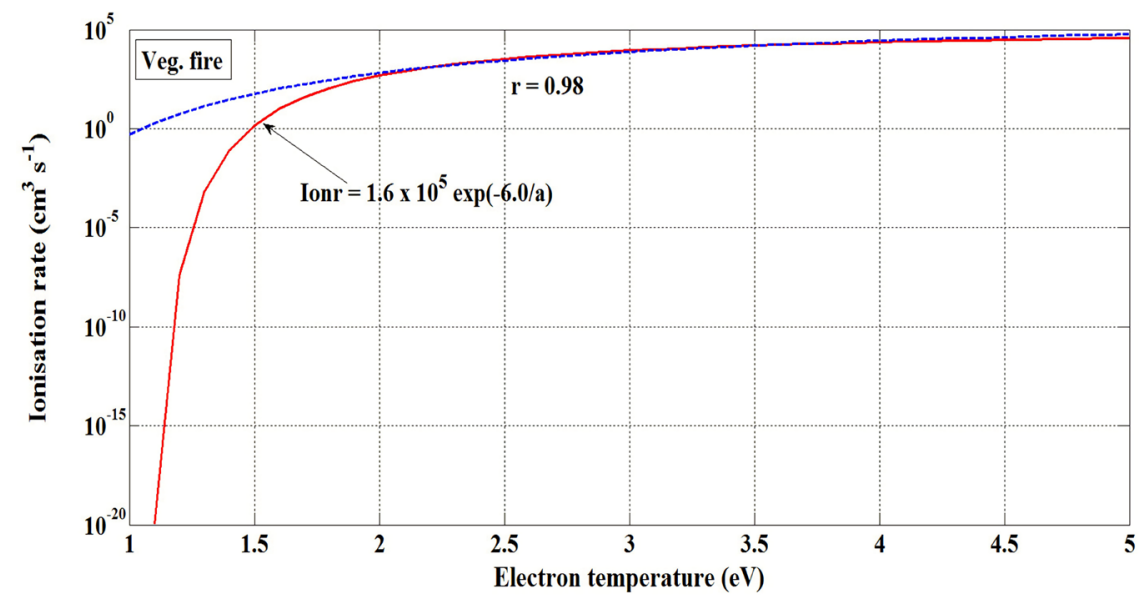

Figure 10. Ionization rate of electrons in vegetation fuel flame (red solid line is for emperical relation and blue dotted line for theoretical relation (after Uhm, 1999)).

Table 2. Constants for attachment and ionization rates in combustion flame.

\begin{tabular}{cc}
\hline Attachment $(\alpha)$ & Ionization $(\alpha)$ \\
\hline$B=57,300$ & $A=1.6 \times 10^{5}$ \\
$b=16.63$ & $a=6.0$ \\
$c=3.14$ & $c=-1$ \\
$r=0.999$ & $r=0.98$ \\
\hline
\end{tabular}

$$
T_{e}=9.14 \times 10^{-5} \frac{E}{P} \frac{\eta T_{r}}{T_{g}}
$$

where $T_{r}=300$ and $\eta=1.5$ are reference temperature and correction term for the constant.

At reference temperature $300 \mathrm{~K}$ and flame temperature of $1300 \mathrm{~K}$, Equation (16) gives breakdown electric field strength of $9.19 \mathrm{kV} / \mathrm{cm}$, a value very close to that obtained by Hirano [29]. The breakdown electric field determined by Hira- 
no is $9 \mathrm{kV} / \mathrm{m}$.

\section{Conclusion}

Two theoretical calculations have been used to determine breakdown electric field strength for vegetation fuel fire. The value has an average of $10.03 \mathrm{kV} / \mathrm{cm}$. However, this value is corroborated by that obtained from experiment on seed flames of about the same temperature, e.g. [29] and [30]. The study considered vegetation fires of temperature range of $625-1300 \mathrm{~K}$ and dielectric field strength was determined to range from $11-18 \mathrm{kV} / \mathrm{cm}$. A nonlinear fit of the experimental data was carried out which gave an empirical expression for breakdown electric field of vegetation fuels fires to be of the form: $E=40 / T_{f l}(\mathrm{kV} / \mathrm{cm})$. The coefficient of the empirical relation is higher than that of dry air. This however is contributed by the fact that fire is made up by several mixture components high molecular weight compared to constituents of dry air.

\section{Conflicts of Interest}

The authors declare no conflicts of interest regarding the publication of this paper.

\section{References}

[1] Flannigan, M., Stocks, B., Turetsky, M. and Wotton, M. (2009) Impact of Climate Change on Fire Activity and Fire Management in Circumboreal Forest. Global Change Biology, 15, 549-560. https://doi.org/10.1111/j.1365-2486.2008.01660.x

[2] Mousa, A.M. (1990) Protecting Firemen against Fire-Induced Flashovers. IEEE Transactions on Power Delivery, 5, 297-302. https://doi.org/10.1109/61.107288

[3] Wu, T., Ruan, J., Hu, Y., Liu, B. and Chen, C. (2011) Study on Forest Fire Induced Breakdown of $500 \mathrm{kv}$ Transmission Line in Terms of Characteristics and Mechanism. Proceedings of the CSEE, 31, 163-170.

[4] Minnaar, U.J., Gaunt, C.T. and Nicolls, F. (2012) Characterisation of Power Systems Events on South African Transmission Power Lines. Electric Power Systems Research, 88, 25-32. https://doi.org/10.1016/j.epsr.2012.01.015

[5] Sukhnandan, A. and Hoch, D.A. (2002) Fire-Induced Flashovers of Transmission Lines: Theoretical Models. 6th Africon Conference in Africa, George, South Africa, 2-4 October 2002, 617-622. https://doi.org/10.1109/AFRCON.2002.1159981

[6] You, F., Chen, H., Zhang, L., Zhang, Y., Zhou, J. and Zhu, J. (2011) Experimental Study on Flashover of High Voltage Transmission Lines Induced by Wood Crib Fire. Proceedings of the Chinese Society of Electrical Engineering, 31, 192-197.

[7] Robledo-Martinez, A. and Guzman, E. (1991) Dielectric Characteristics of a Model Transmission Line in the Presence of Fire. IEEE Transactions on Electrical Insulation, 26, 776-782. https://doi.org/10.1109/14.83702

[8] Diab, R.D., Common, S. and Roberts, L.M. (1991) Power Line Insulator Pollution and Power Dips in Natal, South Africa. Atmospheric Environment, 25A, 2329-2334. https://doi.org/10.1016/0960-1686(91)90107-I

[9] El-Zohri, E.H., Shafey, H.M., Abdel-Salam, M. and Ahmed, A. (2011) Mathematical Modeling of Agricultural Fires Beneath High Voltage Transmission Lines. Energy, 36, 385-396. https://doi.org/10.1016/j.energy.2010.10.027 
[10] Wu, T., Ruan, J., Chen, C. and Huang, D. (2011) Field Observation and Experimental Investigation on Breakdown of Air Gap of A.C. Transmission Line under Forest Fires. 2011 IEEE Power Engineering and Automation Conference (PEAM), Wuhan, 8-9 September 2011, 339-343.

[11] Maabong, K., Mphale, K., Letsholathebe, D. and Chimidza, S. (2018) Measurement of Breakdown Electric Field Strength for Vegetation and Hydrocarbon Flames. Journal of Electromagnetic Analysis and Applications, 10, 53-66. https://doi.org/10.4236/jemaa.2018.103004

[12] Morvan, D. and Dupuy, J.L. (2004) Modeling the Propagation of Wildfire through a Mediterranean Shrub Using a Multiphase Formulation. Combustion and Flame, 138, 199-210. https://doi.org/10.1016/j.combustflame.2004.05.001

[13] Garcia, R., Pizarro, C., Lavin, A.C. and Bueno, J.L. (2013) Biomass Proximate Analysis Using Thermogravimetry. Bioresource Technology, 139, 1-4. https://doi.org/10.1016/j.biortech.2013.03.197

[14] Nussbaumer, T., (2003) Combustion and Co-Combustion of Biomass: Fundamentals, Technologies, and Primary Measures for Emission Reduction. Energy and Fuels, 17, 1510-1521. https://doi.org/10.1021/ef030031q

[15] Reid, J.S., Koppmann, R., Eck, T.F. and Eleuterio, D.P. (2005) A Review of Biomass Burning Emissions Part II: Intense Physical Properties of Biomass Particles. Atmospheric Chemistry and Physics, 5, 799-825. https://doi.org/10.5194/acp-5-799-2005

[16] Latham, D. (1999) Space Charge Generated by Wind Tunnel Fires. Atmospheric Research, 51, 267-278. https://doi.org/10.1016/S0169-8095(99)00012-5

[17] Mphale, K.M., Luhanga, P.V.C. and Heron, M.L. (2008) Microwave Attenuation in Forest Fuel Flames. Combustion and Flame, 154, 728-739.

https://doi.org/10.1016/j.combustflame.2008.07.006

[18] Mphale, K.M., Heron, M., Ketlhwaafetse, R. and Letsholathebe, D. (2010) Inteferometric Measurement of Ionisation in a Grassfire. Meteorology and Atmospheric Physics, 106, 191-203. https://doi.org/10.1007/s00703-010-0061-4

[19] Okuno, T., Sonoyama, N., Hayashi, J., Li, C., Sathe, C. and Chiba, T. (2005) Primary Release of Alkali and Alkaline Earth Species during Pyrolysis of Pulverized Biomass. Energy and Fuel, 19, 2164-2171. https://doi.org/10.1021/ef050002a

[20] Vodacek, A., Kremens, R.L., Fordham, S.C., VanGorden, S.C., Luisi, D., Schott, J.R. and Latham, D.J. (2002) Remote Optical Detection of Biomass Burning Using Potassium Emission Signature. International Journal of Remote Sensing, 23, 2721-2726. https://doi.org/10.1080/01431160110109633

[21] Sorokin, A., Vancassel, X. and Mirabel, P. (2002) Emission of Ions and Charged Soot Particle by Aircraft Engines. Atmospheric Chemistry and Physics Discussions, 2, 2045-2074. https://doi.org/10.5194/acpd-2-2045-2002

[22] Letsholathebe, D. and Mphale, K. (2013) Microwave Phase Perturbation and Ionisation Measurement in Vegetation Fire Plasma. IET Microwaves, Antennas and Propagation, 7, 741-745. https://doi.org/10.1049/iet-map.2012.0468

[23] Uhm, H.S. (1999) Properties of Plasma Generated by Electrical Breakdown in Flames. Physics of Plasmas, 6, 4366-4374. https://doi.org/10.1063/1.873701

[24] Ferguson, S., Dahale, A., Shotorban, B., Mahalingam, S. and Weise, D.R. (2013) The Role of Moisture on Combustion of Pyrolysis Gases in Wildland Fires. Combustion Science and Technology, 185, 435-453. https://doi.org/10.1080/00102202.2012.726666

[25] Zhou, S. and Mahalingam, S. (2001) Evaluation of Reduced Mechanism for Model- 
ing Combustion of Pyrolysis Gas in Wildland Fire. Combustion Science and Technology, 117, 39-70. https://doi.org/10.1080/00102200108907858

[26] Morley, C. (2004) GASEQ Version 0.78. http://www.gaseq.co.uk/

[27] Itikawa, Y. (1973) Effective Collision Frequency of Electrons in Gases. Physics of Fluids, 16, 831-835. https://doi.org/10.1063/1.1694435

[28] Heylen, A.E.D. and Lewis, T.J. (1956) The Electric Strength of Hydrocarbon Gases. British Journal of Applied Physics, 7, 411-415. https://doi.org/10.1088/0508-3443/7/11/306

[29] Hirano, T. (1973) Breakdown Potential of Potassium Seeded Combustion Products. Combustion and Flame, 21, 231-240. https://doi.org/10.1016/S0010-2180(73)80027-6

[30] Chandra, A., Dahiya, R.P., Raju, G.V.R. and Gupta, R.G. (1980) Cathode Sheaths in Potassium Seeded MHD Combustion Plasma. Journal of Physics D: Applied Physics, 13, 1211-1219. https://doi.org/10.1088/0022-3727/13/7/016

[31] Chen, S., Zeng, R. and Zhuang, C. (2013) The Diameter of Long Positive Streamers in Atmospheric Air under Lightning Impulse Voltage. Journal of Physics D: Applied Physics, 46, 375 203. https://doi.org/10.1088/0022-3727/46/37/375203

[32] Qin, J. and Pasko, V.P. (2014) On the Propagation of Streamers in Electrical Discharges. Journal of Physics D: Applied Physics, 47, Article ID: 435202. https://doi.org/10.1088/0022-3727/47/43/435202

[33] Boan, J. (2007) Radio Experiment with Fire. IEEE Antennas and Wireless Propagation Letter, 6, 411-414. https://doi.org/10.1109/LAWP.2007.902809

\section{List of Symbols}

\begin{tabular}{|c|c|}
\hline A: ionization coefficient & \\
\hline B: attachment coefficient & \\
\hline d: inter-electrode distance & Greek \\
\hline e: electron charge & \\
\hline E: electric field intensity & $\alpha$ : ionization rate \\
\hline$E_{0}:$ initial electric field intensity & $\beta:$ attachment rate \\
\hline$E_{b r}:$ breakdown field strength & $\delta$ : ionization potential factor \\
\hline$F_{b r}:$ braking force & $\gamma \cdot$ electron affinity factor \\
\hline$f_{0}:$ propagation frequency & $\sigma$. electrical conductivity \\
\hline J: current density & $\sigma_{i}:$ imaginary component of $\sigma$ \\
\hline$k_{B}:$ Boltzmann constant & $\sigma_{r}:$ real component of $\sigma$ \\
\hline$m_{e}:$ electron mass & $\varphi_{\text {eff }}$ effective collision frequency \\
\hline$n_{i}$ : number density of ${ }^{\text {th }}$ component & $\omega=2 \pi f_{0}:$ angular frequency \\
\hline$n_{e^{:}}$electron density & \\
\hline$N_{g}$ : background gas density & \\
\hline$q_{e}:$ electron charge & Mathematical \\
\hline$Q_{i}:$ collision cross section of $I^{\text {th }}$ component & \\
\hline r. electron position vector & d/ dt: time derivative \\
\hline$r_{s}:$ streamer radius & $i=\sqrt{1}:$ imaginary \\
\hline t: time & \\
\hline$T_{f f}$ fire temperature & \\
\hline$u_{d}:$ drift velocity & \\
\hline$u_{s}:$ streamer velocity & \\
\hline
\end{tabular}

